\title{
ISOTOPE RATIOS OF LARGE ICE MASSES
}

\author{
By A.S. JONES
}

(Department of Mathematics, University of Queensland, St Lucia, Queensland 4067, Australia)

\begin{abstract}
A model is proposed for determining the relative proportions of ${ }^{16} \mathrm{O}$ and ${ }^{18} \mathrm{O}$ in large ice sheets. Values calculated using this model are in agreement with published values for Antarctica and Greenland. It is intended to use the model for comparisons between the known ocean isotopic records and postulated ice-sheet masses during the last ice age.
\end{abstract}

RÉsumE. Teneur isotopique des indlandsis. On propose un modèle permettant de déterminer les teneurs relatives en ${ }^{16} \mathrm{O}$ et ${ }^{18} \mathrm{O}$ dans les calottes polaires. Ces valeurs calculées selon ce modèle sont en accord avec les valeurs publiées pour l'Antarctique et le Groenland. On se propose d'utiliser ce

\section{INTRODUCTION}

Oxygen occurs naturally as three isotopes. The most common of these is ${ }^{16} \mathrm{O}$, the remainder consisting mainly of ${ }^{18} \mathrm{O}$ with a small proportion of ${ }^{17} \mathrm{O}$. When formed into water, the resulting "light" and "heavy" fractions have different properties with respect to evaporation and condensation, the light fraction evaporating more readily than the heavy, while precipitation favours the heavy fraction.

Where the rain (or melting snow) returns to the oceans in a comparatively short time, these properties have no appreciable effect on the proportions of the isotopes found in sea-water, but the presence of large ice masses such as in Antarctica and Greenland at the present time, and the large ice sheets which formed during the last ice age, have quite significant effects. Furthermore, these effects can be measured by studying sea-shells which have incorporated oxygen from sea-water in the ratios present at their time of formation (Emiliani, 1955; Shackleton and Opdyke, 1973). The variation of these isotope ratios during the last 120000 years, covering the period of the last ice age, is therefore known reasonably accurately. On the other hand, rates of growth and decay of the large ice masses during this period are largely conjectural. A formula for predicting the proportions of the isotopes in large ice masses can be used in conjunction with a selection of these conjectures to determine the corresponding variations in sea-water ratios and, by comparison with the known data, select those conjectures which lead to the most accurate predictions.

Large ice masses act as light-isotope reservoirs in two ways. First, the snow which precipitates to form the ice naturally contains a higher proportion of light isotope than sea-water due to the preferential evaporation of the light isotope in the water vapour forming the clouds. This effect is enhanced by the fact that the heavy-isotope snow falls preferentially close to the ice margin, leaving increasingly higher proportions of light isotope in the precipitate moving inland. Also, near the margin, the ice velocities are higher and the time taken for the ice to return to the ocean is of the order of decades rather than millennia. The combination of these factors means that the larger the ice sheet, the higher the proportion of light isotope it contains.

\section{THE MATHEMATICAL MODEL}

In order to model the amount of light isotope in an ice mass, it is necessary to make assumptions concerning the modèle pour comparer les compositions isotopiques océaniques connues aux compositions isotopiques postulées pour les indlandsis pendant la dernière glaciation.

ZUSAMMENFASSUNG. Isotopenverhältnisse grosser Eismassen. Zur Bestimmung der relativen Anteile von ${ }^{16} \mathrm{O}$ und ${ }^{18} \mathrm{O}$ in grossen Eisschilden wird ein Modell vorgeschlagen. Die mit diesem Modell berechneten Werte stimmen mit solchen überein, die für Antarktika und Grönland veröffentlicht wurden. Es ist beabsichtigt, das Modell für Vergleiche zwischen bekannten Isotopenaufzeichnungen der Ozeane und postulierten Eisschildmassen wăhrend der letzten Eiszeit heranzuziehen.

variations of the isotope in the precipitate, the pattern of precipitation over the ice mass, and the shape and dynamic properties of the ice mass.

The relative abundances of the three oxygen isotopes are stated variously as

$99.5186: 0.0746: 0.4068$ (Trigg, 1963),

or $99.759: 0.037: 0.204 \quad(\mathrm{Nier}, 1950)$,

of which the values given by Nier are those generally accepted.

Using Nier's figures for air, Dansgaard (1954) calculated that the ${ }^{18} \mathrm{O}$ abundance of unmixed ocean water should be 0.1991 atom \%. Since there is no available information on variations of ${ }^{17} \mathrm{O}$, it is assumed that the ratio of the isotopes in sea-water are 99.7639:0.037 : 0.1991 .

The corresponding ${ }^{18} \mathrm{O}$ abundance in atmospheric water vapour is somewhat less (about 0.1973 atom \%; Dansgaard (1954)), so that the precipitate is deficient in ${ }^{18} \mathrm{O}$, and this deficiency increases moving away from the moisture source, since the ${ }^{18} \mathrm{O}$ present is water vapour is preferentially precipitated. Koerner (1979) proposed a linear relation for 8 (the relative variation in the ratio of ${ }^{18} \mathrm{O} /{ }^{16} \mathrm{O}$ ) as a function of distance from the moisture source, but data supplied by Dr G.S. Boulton (personal communication) suggests that an exponential curve is more appropriate, giving as a model for the ratio $\rho\left(={ }^{16} \mathrm{O} /\left({ }^{16} \mathrm{O}+{ }^{18} \mathrm{O}\right)\right)$ in the precipitate at a distnce $d$ inland in the form

$$
\rho=\alpha-\beta \mathrm{e}^{-\gamma d} \text {. }
$$

Using the isotopic values for Antarctica reported by Morgan (1982), the values of the parameters were calculated as

$$
\alpha=0.99811817, \beta=0.00006986, y=1.65 / 1000 \mathrm{~km} \text {. }
$$

Greatest precipitation on large ice masses occurs at the margins. The simplest (mathematically) way of modelling this behaviour is to make the precipitation proportional to $r^{n}$, where $r$ is the distance from the centre of the ice and $n$ is a positive integer. (The case $n=0$, which corresponds to uniform precipitation over the whole ice mass, will also be considered as an extreme possibility.)

Finally, for simplicity, we consider a circular ice mass of uniform thickness. The assumption of uniform thickness is reasonable in the sense that the surface slopes of large 
ice masses are very small, except at their margins. Dynamically, we assume that the horizontal velocity is uniform with respect to depth and that the ice mass is in a steady state. Loss of ice, to compensate for that gained by precipitation, is assumed to occur by calving at the margins, so that there is no ablation from the upper surface of the ice.

Denoting the ice thickness by $h$, the horizontal radius of the ice mass by $R$, and the radial and vertical coordinate variables by $r$ and $y$, respectively, we obtain the following results.

Assuming that the horizontal velocity is a function of $r$ alone, the continuity equation

$$
\frac{\partial v}{\partial y}+\frac{1}{r} \frac{\partial}{\partial r}(r u)=0
$$

(where $u$ and $v$ are the radial and vertical velocity components, respectively) implies that

$$
v=\left[-\frac{1}{r} \frac{\partial}{\partial r}(r u)\right] y
$$

where we have used the boundary condition $v=0$ at the base of the ice. At the surface $y=h$, the vertical velocity must equal the accumulation rate for a steady-state model, therefore we have

$$
-\frac{1}{r} \frac{\partial}{\partial r}(r u) h=-c r^{n}
$$

giving

$$
v=-c r^{n}\left(\frac{\gamma}{h}\right)
$$

and

$$
u=\frac{c}{h} \frac{r^{n+1}}{(n+2)}
$$

Within the ice, the proportion $\rho(r, y)$ of light isotope will be constant along the stream lines and will take the values corresponding to the intersections of the stream lines with the surface.

The stream lines are given by the differential equation

$$
\frac{\mathrm{d} y}{\mathrm{~d} r}=\frac{v}{u}=-\frac{(n+2) y}{r},
$$

the solution of which is

$$
y r^{n+2}=\text { constant. }
$$

If this stream line intersects the surface at $\left(r_{0}, h\right)$,

$$
r_{0}=r\left[\frac{y}{h}\right]^{1 /(n+2)},
$$

and the corresponding value of $\rho$ is

$$
\rho=\alpha-\beta \mathrm{e}^{-y\left(R-r_{0}\right)} .
$$

Hence the proportion of light isotope within the ice mass will be

$$
\rho(r, y)=\alpha-\beta \mathrm{e}^{-y R} \exp \left(y r(y / h)^{1 /(n+2)}\right) .
$$

Hence we obtain the total amount of light isotope trapped within the ice as

$$
\begin{aligned}
T=2 \pi \int_{0}^{h} \mathrm{~d} y \int_{0}^{R} r \mathrm{~d} r \rho(r, y) \\
=2 \pi \int_{0}^{h} \mathrm{~d} y \int_{0}^{R} r \mathrm{~d} r\left(\alpha-\beta \mathrm{e}^{-y R} \mathrm{e}^{A r}\right) \\
\quad(\text { where } A=y(y / h) 1 /(n+2) \\
=\pi R^{2} h \alpha-2 \pi \beta \mathrm{e}^{-y R} \int_{0}^{h} \mathrm{~d} y \int_{0}^{R} \mathrm{~d} r r \mathrm{e}^{A r} \\
=\pi R^{2} h \alpha-2 \pi \beta \mathrm{e}^{-y R} \int_{0}^{h} \mathrm{~d} y\left[R \frac{\left.\mathrm{e}^{A r}-\frac{\mathrm{e}^{A R}-1}{A}\right] .}{A^{2}}\right]
\end{aligned}
$$

Changing the variable of integration by setting $s=A R$, this reduces to

$$
\begin{aligned}
T & =\pi R^{2} h\left[\alpha-\beta \frac{2(n+2) \mathrm{e}^{-\gamma R}}{(y R)^{n+2}} \int_{0}^{y R} \mathrm{~d} s s^{n-1}\left((s-1) \mathrm{e}^{s}+1\right]\right) \\
& =\pi R^{2} h\left(\alpha-\beta g_{n}(y R)\right) .
\end{aligned}
$$

The function

$$
g_{n}(x)=\frac{2(n+2) \mathrm{e}^{-x}}{x^{n+2}} \int_{0}^{x} \mathrm{~d} s s^{n-1}\left[(s-1) \mathrm{e}^{s}+1\right]
$$

reduces to an expression involving polynomials and exponentials if $n$ is a positive integer,

$$
\text { i.e. } g_{1}(x)=6\left[(2+x) \mathrm{e}^{-x}-(2-x)\right] / x^{3} \text {, }
$$

but for the case $n=0$ there is no such expression in closed form, although it can be represented as

$$
g_{0}(x)=\sum_{m=0}^{\infty} \frac{4}{(m+2) !}(-x)^{m}\left[\frac{1}{2}+\frac{1}{3}+\ldots+\frac{1}{m+2} .\right.
$$

For large values of $x$,

$$
g_{n}(x) \sim \frac{2(n+2)}{x^{2}}-\frac{2(n+2)(n+1)}{x^{3}}+O\left(x^{-4}\right),
$$

indicating that concentrating the precipitation close to the margin reduces the overall proportion of light isotope in the ice mass.

The other interesting feature of this solution is that the proportion of light isotope in the mass depends only on the lateral extent of the ice mass, the ice thickness $h$ only appearing in the volume factor.

\section{PRESENT-DAY ICE SHEETS}

The two great ice sheets, covering Antarctica and Greenland, contain approximately $99 \%$ of the ice at present occurring in the world. Of this, approximately $28 \times 10^{6} \mathrm{~km}^{3}$ is found in Antarctica and approximately 2.5 $x 10^{6} \mathrm{~km}^{3}$ in Greenland. The surface area of Antarctica is approximately $13 \times 10^{6} \mathrm{~km}^{2}$, giving an effective value for $R$ of $2000 \mathrm{~km}$, while the ice cover of Greenland is approximately $1.81 \times 10^{6} \mathrm{~km}^{2}$, giving $R=760 \mathrm{~km}$. Substituting these values into the formula derived above, we obtain the values listed in Table I for the proportions of light isotope held in these systems, together with the corresponding values of $\delta$.

Published data for Antarctica (Schwerdtfeger, 1970) 
TABLE I

\begin{tabular}{|c|c|c|c|c|c|c|c|c|}
\hline \multirow[b]{2}{*}{$n$} & \multicolumn{4}{|c|}{ Antarctica } & \multicolumn{4}{|c|}{ Greenland } \\
\hline & $g_{n}$ & $\alpha-$ & $\beta g_{n}$ & 8 & $g_{n}$ & $\alpha-\beta$ & $g_{n}$ & 8 \\
\hline 0 & 0.213005 & 0.9981 & 0339 & -47.80 & 0.519481 & 0.9980 & 8188 & -37.03 \\
\hline 1 & 0.249684 & 0.9981 & 0073 & -46.51 & $0.555 \quad 490$ & & 7936 & -35.77 \\
\hline 2 & $0.275 \quad 241$ & 0.9980 & 9894 & -45.61 & $0.578 \quad 453$ & & 7776 & -34.96 \\
\hline 3 & $0.294 \quad 207$ & & 9762 & -44.95 & 0.594443 & & 7664 & -34.40 \\
\hline 4 & $0.308 \quad 896$ & & 9659 & -44.43 & 0.606245 & & 7582 & -33.98 \\
\hline 5 & $0.320 \quad 637$ & & 9577 & -44.02 & 0.615325 & & 7518 & -33.66 \\
\hline 6 & $0.330 \quad 249$ & & 9510 & -43.68 & 0.622534 & & 7468 & -33.41 \\
\hline 7 & $0.338 \quad 273$ & & 9454 & -43.40 & $0.628 \quad 400$ & & 7427 & -33.20 \\
\hline 8 & $0.345 \quad 076$ & & 9406 & -43.16 & 0.633262 & & 7393 & -33.03 \\
\hline 9 & 0.350920 & & 9365 & -42.95 & 0.637409 & & 7364 & -32.89 \\
\hline 10 & 0.355997 & 0.9980 & 9330 & -42.78 & 0.640555 & 0.9980 & 7342 & -32.78 \\
\hline
\end{tabular}

suggest that a reasonable value of $n$ is 2 but, as can be seen from the table, there is only a $3 \%$ difference in the estimated values for Antarctica for $n$ between 1 and 3, and only a $4 \%$ difference for Greenland over the same range, so that the choice is not critical.

\section{CONCLUSION}

The model proposed produces realistic values for the ${ }^{18} \mathrm{O}$ deficiency of the Antarctic and Greenland ice sheets. The principal advantage of the model for computational purposes is that it requires only a knowledge of the ice volume and mean radius of the ice sheet for its implementation. The only parameter which needs to be used is that defining the precipitation profile and, as has been noted, the results are not critically dependent on this. The model is "steady state" to the extent that it assumes that the ice sheet is neither growing nor decaying. However, the constant of proportion in the precipitation function can be replaced by an arbitrary function of time without affecting the results, provided the precipitation profile is the same (i.e. $n$ is constant).

For growing or decaying ice sheets, a full mathematical treatment along the same lines is hampered by lack of information about the relative effects of increasing/decreasing precipitation and increasing/decreasing ice loss at the margins as the controlling mechanisms. It is to be expected that a growing ice sheet would contain relatively less light isotope than that predicted by this model and a decaying ice sheet relatively more. However, since there is no procedure for calculating these variations, this model at least offers a workable method of estimating the isotopic composition in this case.

\section{REFERENCES}

Dansgaard, W. 1954. The $\mathrm{O}^{18}$-abundance in fresh water. Geochimica et Cosmochimica Acta, Vol. 6, No. 4, p. 241-60.

Emiliani, C. 1955. Pleistocene temperatures. Journal of Geology, Vol. 63, No. 6, p. 538-78.

Koerner, R.M. 1979. Accumulation, ablation, and oxygen isotope variations on the Queen Elizabeth Islands ice caps, Canada. Journal of Glaciology, Vol. 22, No. 86, p. $25-41$.

Morgan, V.I. 1982. Antarctic ice sheet surface oxygen isotope values. Journal of Glaciology, Vol. 28, No. 99, p. 315-23.

Nier, A.D. 1950. A redetermination of the relative abundances of the isotopes of carbon, nitrogen, oxygen, argon, and potassium. Physical Review, Vol. 77, No. 6, p. 789-93.

Schwerdtfeger, W. 1970. The climate of the Antarctic. (In Landsberg, H.E., ed. World survey of climatology. Amsterdam, Elsevier, Vol. 14, p. 253-355.)

Shackleton, N.J., and Opdyke, N.D. 1973. Oxygen isotope and palaeomagnetic stratigraphy of Equatorial Pacific Core V28-238: oxygen isotope temperatures and ice volumes on a $10^{5}$ year and $10^{6}$ year scale. Quaternary Research, Vol. 3, No. 1 , p. 39-55.

Trigg, G.L. 1963. Systematics of stable nuclei. (In American Institute of Physics handbook. Second edition, chapter 8b, p. $8-4-8-20$.) 